\title{
Benefits Measurement of a Plan to Reduce Hypertension in a Healthcare Foundation Using the BCTool
}

\author{
Leandro Pereira, ISCTE, Winning LAB, Instituto Universitário de Lisboa, Portugal \\ (iD) https://orcid.org/0000-0002-4920-0498 \\ Vânia Patrício, ISCTE, Winning LAB, Instituto Universitário de Lisboa, Portugal \\ António Fernandes, ISCTE, Winning LAB, Instituto Universitário de Lisboa, Portugal \\ José Santos, ISCTE, Winning LAB, Instituto Universitário de Lisboa, Portugal \\ (iD) https://orcid.org/0000-0003-3543-3570 \\ Ricardo Santos, ISCTE, Winning LAB, Instituto Universitário de Lisboa, Portugal \\ Carlos Jerónimo, ISCTE, Winning LAB, Instituto Universitário de Lisboa, Portugal \\ (iD) https://orcid.org/0000-0002-8265-2840 \\ Francisco Simões, ISCTE, Winning LAB, Instituto Universitário de Lisboa, Portugal
}

\begin{abstract}
Hypertension is a well-known problem and associated with high salt consumption. To measure the impact of salt consumption, the methodology provided by the business case tool (BC Tool) has been applied in a Portuguese foundation for the elderly in order to contribute to the intervention plan for the reduction of hypertension, which aims to reduce salt consumption in the Portuguese population and to improve the control of hypertension through a phased reduction in salt consumption. This objective has been achieved by changing the availability of foods with lower salt content and by decreasing the addition of salt in cooking. The results of these measures provided a substantial benefit in terms of benefits measurements and cost analysis besides the results of SROI measurement in order to obtain the social benefits of this initiative of the intervention plan to reduce hypertension. Along these results, suggestions for improvements that would allow the Sarah Beirão Foundation's response to the needs of its users to be improved are shown.
\end{abstract}

\section{KEYWORDS}

BcTool, Benefits, Business Case, Healthcare

\section{INTRODUCTION}

The elevated blood pressure is responsible, globally, for $62 \%$ of cerebrovascular disease and $49 \%$ of ischaemic heart disease (Ha, 2014). The World Health Organization (WHO) strongly recommended to reduce dietary salt intake as one of the top priority actions in order to decrease the number of deaths from hypertension (WHO report 2007) since is one of the leading causes of death worldwide (Alwan, 
2011; WHO, 2014). Is well known that salt excessive consumption is one of the most important factors of high blood pressure and increased cardiovascular risk (Cappuccio, 2013). For instance, the hypertension is one of the main causes of excessive consumption of salt (also known by its chemical name, sodio chloride), which is evident by several epidemiological, experimental, and clinical studies which positively correlates with excessive salt consumption (Alawwa et al., 2018). The hypertension, associated with consumption of salt, studied in this paper is one of the commonest chronic diseases (Singh et al., 2016) and is usually accompanied by several other diseases associated, such as hearth and vascular disease, stroke and renal failure (Turner et al., 2008).

A considerable and reliable methodology to measure the salt consumption and reducing it in a certain place is obtained with a comprehensive Business Case. A Business Case provides justification for undertaking a project, programme or portfolio. It evaluates the benefit, cost and risk of alternative options and provides a rationale for the preferred solution (APM, 2019). Business Case is an independent and rigorous evaluation process of an initiative that aims value creation in the organisation through the application of its financial, human and time means, or in other words, a Business Case consists on a decision-making tool to determine whether an investment will create value (BcBok, 2015). Typically, it consists on a well-structured document where it states the investment purpose followed by the business impacts estimation (benefits) and costs in order to determine whether the decision under analysis will be profitable. A Business Case should be free of non-validated assumptions, following a rational and impartial process allowed by the usage of business research methods to validate cause-effect relations between phenomena.

Since the business need may come from different possible origins, either top down, bottom-up, middle management or even triggered from external sources, it is essential that a benefits mind-set is "educated" across the organization's teams so they clearly understand the value of their innovative contributions and initiative proposals. Once the business needs are identified, the business case becomes helpful on providing insightful data on which solutions proposed will better suit the problem, need or opportunity reported and how much value they will return, maximizing the Return on Investment (ROI), and consequently support top management decisions on knowing what, how and when to invest resources towards maximizing business value. Although, and depending the study purpose it could be applied the Social Return on Investment (SROI) since it's focused in the social aspect.

In addition to this less responsible practice in many organisations, the validation of truthfulness and accuracy becomes more difficult because the variables and the context are so volatile that when the time to measure the results comes, we either do not measure them or anchor our justification in exogenous conditions in which we are immersed and that it was very difficult to predict any kind of change. It is essential to guarantee that the initial moment of Business Case configuration does not stand on assumptions or emotional expectations, but on estimates obtained through proven and free processes, which can contribute to a successful business implementation.

The Business Case methodology is already applied to several healthcare issues (Gomes et al., 2019; Chin, 2016) in order to prevent, diagnose or provide better decision-making (Zwetsloot et al., 2007) which can contribute significatively to a healthcare better decision. The initiative "Intervention Plan for the reduction of hypertension" appears as a response to the increase in salt consumption, an emerging problem in Portugal. In this sense, an initiative adopted is to reduce salt consumption, improving Hypertension (HTA) control through a phased reduction of salt. This objective would be achieved by changing the availability of foods with a lower salt content and by reducing the addition of salt in cooking.

This paper aims to reply to a considerable healthcare problem, namely the hypertension associated with the salt consumption in elderly people in specific foundation which has been facing several healthcare problems (hypertension) in their patients associated with the current meals served and the lack of preparation and measurement in terms of health impact and quality of life. Thus, in this paper, it has been measured the benefits of an intervention plan to reduce HTA in a specific 
foundation following several actions, which will be described in the section 3 , and measuring tangible and intangible benefits. To achieve and measure such benefits it has been applied a framework called Business Case Tool (BC Tool). This framework aims to support the decision-making process regarding the implementation of a successful business strategy. This tool is considerable eclectic and can be applied to several vertical markets. The purpose of this Business Case Tool is to apply several algorithms to choose the best investment decision, rather than relying only on traditional evidence and methods like ROI calculation. In order to quantify the benefits of the social impact between cost and benefits, in this particular case, it has been applied the SROI. This methodology applied with the adopted actions manage to reduce the levels of hypertension, increase the quality of life besides motive the patients to a better and sustainable life. The measurement of those actions using a disruptive tool to evaluate the benefits contributed to the current state of art, regarding healthcare overcome, benefits increase and cost reduction besides social awareness increase, due to innovative approach.

This paper is organized as follow, it will be described in the literature review the current status of art of Business Case, its structure, framework and current evolution of the traditional Business Cases with the development of the BC Tool. The following section described the adopted methodology followed by the results section, with emphases in output from the Benefits measurements, Cost analysis, SROI and questionaries reply. The last sections are the conclusions, future work and limitations of the work which could be overcome.

\section{LITERATURE REVIEW}

\section{Business Case}

The conceptualization and the benefits of an implementation of a Business Case in the Healthcare sector is mentioned by several authors (Baker et al., 2016; Luck et al., 2007). The methodology of the Business Case can be applied from public hospital to private hospitals where the core business is different in terms of investment and management. The business case can address several topics within the healthcare sector. For instance, it can address physician burnout since its ability to includes costs associated with turnover and lost revenue associated with decreased productivity, as well as financial risk and threats to the organization's long-term viability can be measured by its benefits (Shanafelt et al., 2017). Another subject is the benefit measurement of cost/benefit analysis for an electronic hospital information system (Garrido et al., 2004) or when it's needed to measure the impact, cost and benefits of build a new hospital or to renovate an existing facility (Sadler et al., 2008). The Business Case should contribute not only to the benefit measurements has mentioned before but also to the success and the mitigation of risk or failure in different ways, which should be considered by the stakeholders, namely the creation, review and update of the business case during a timeline, stakeholders understanding of the project's ongoing, benefits, costs and risks, thus, a complete information scheme which will allow the stakeholders to take well-informed decisions (Ward et al., 2008; Einhorn et al., 2019).

\section{Business Case, Phase Assessment and Benefits}

To have a proper Business Case implemented there are three main phases equally relevant and supported by the organisation's strategy:

Phase 1: Project Justification

Phase 2: Project Implementation

Phase 3: Benefits Measurement

Once the different phases are completed the organizations, managed by the project manager who has overall accountability for realizing the benefits (Olsson, 2018; Zwikael et al., 2018), should 
be able to achieve several objectives. For instance, having the three phase's execution allied to the good business case practices, the organisation will be able to achieve several objectives, such as: Provide the organisation with technical and managerial highly proven tools within the business and scientific worlds; Avoid / Restrict any the human component of initiatives' analysis, by implementing an effective business case where two different people or teams, in the same circumstances, will reach the same conclusion about the project return; Minimise assumptions and projects subjectivity during project analysis; Get the organisation to read, interpret and anticipate market needs, leveraging the number of initiatives proposed; Ensure projects proposals are aligned with the strategic objectives and contribute to achieve them; Support the decision-making process in order to be fair, rational and able to ensure the creation of value, avoiding unwanted outcomes in project results at the benefits' realisation stage; Support business managers on how to apply resources to maximise creation of wealth and organisational efficiency; Encourage and increase the corporate intelligence through proposals and initiatives that add value. Promoting a culture of participation is an essential step for the continuous process of value proposals; Stimulate a benefits management culture by setting the available budget based on value propositions submitted by departments and the estimated benefits and to provide the ability to measure the project benefits during the exploitation period.

To measure the benefits of a Business Case it is used the Return on Investment. The primary goal of the ROI model is to provide a quantified assessment of the anticipated value-added from the Business Case deployment, specifically to estimate both the cost and net benefit expected (Palmer et al., 2009). The ROI calculation of a project consists of three main components which must be accurately estimated and obtained through proven processes:

- Investment Plan: It is the budget required to implement the project and develop the asset for exploitation. If the cost reached is higher than the budget, then the ROI is smaller.

- Benefit Plan: It is the impact observed in the value creation dimensions (revenue growth, cost reduction, efficiency and legal compliance). If the benefit reached is lower than the estimated, the ROI is lower.

- Plan for New Operating Costs: It's the new operating cost and recurrence in which the organisation has to incur to ensure that the product or service is properly exploited. If the new operating cost reached is higher than estimated, the ROI is lower.

Hence ROI is calculated as follows:

$$
R O I=\frac{\text { Benefits }- \text { Operational Costs }}{\text { Investment }}-1
$$

Note that the cost of the Business Case development process must not be considered in the ROI analysis, as it is a sunk cost, i.e. it is a cost that has already occurred, and it was essential for the organisation to make a decision. It is, thus, positioned as a cost management, overhead. Although ROI is largely used in the world of finance to measure the efficiency of investments (Charles et al., 2019) and is calculated as the net value of the investment/cost of the investment, where the net value of the investment is the current value of the investment - cost of the investment (Fischer et al., 2020), in this paper it has been applied, instead, the Social Return on Investment (SROI) since it takes the concept of measurement a step further and takes into account the Social impacts of projects (Charles et al., 2019). The SROI is a framework for measuring and accounting for this much broader concept of value; it seeks to reduce inequality and environmental degradation and improve wellbeing by incorporating social, environmental and economic costs and benefits (Nicholls, 2017).

Thus, the Benefits Measurement of the present case are compliance with the SROI since it takes into account the social impacts of benefits in salt reduction. According to the A Guide to Social Return 
on Investment (UK Cabinet Office, 2012) the outcome provided by SROI can help develop strategies to increase the social and environmental value that the organization creates, manage activities by comparing performance with forecasts and help communicate with funders and beneficiaries. For instance, the author Gosselin et al., (2020) applied a SROI framework to inform policy-making relating with the benefits of the Physical Activity and Sport (PAS) investment. Also the author Merino et al., (2020) applied the SROI to measure the social impact that health proposals would generate to improve the current management of heart failure (HF) within the Spanish National Health System (SNHS).

The SROI is calculated according the following formula:

$S R O I=\frac{S I V-I I A}{I I A \times 100 \%}$

where:

SIV = Social Impact Value

IIA = Initial Investment Amount

\section{Business Case Framework}

The Business Case Body of Knowledge is a methodology composed by a set of knowledge, skills, tools and techniques which, when appropriately applied in any given initiative, it enhances the chances of a successful management decision towards a project investment (BcBOK, 2015). The framework (Figure 1) is composed by eight main steps (Project Request, Strategic Alignment, Benefits Estimation, Cost Estimation, Economic Evaluation, Contex Readiness, Decision Making and Benefits Tracking) and aims to assess the feasibility of an initiative (investment), or in other words, if it creates value to the organisation.

The figure 1 shows the major steps, which will be explained in the next chapter 2.3 (table 1 ) that create the business case process and related inputs, tools and techniques recommended, followed by

Figure 1. Business Case Framework

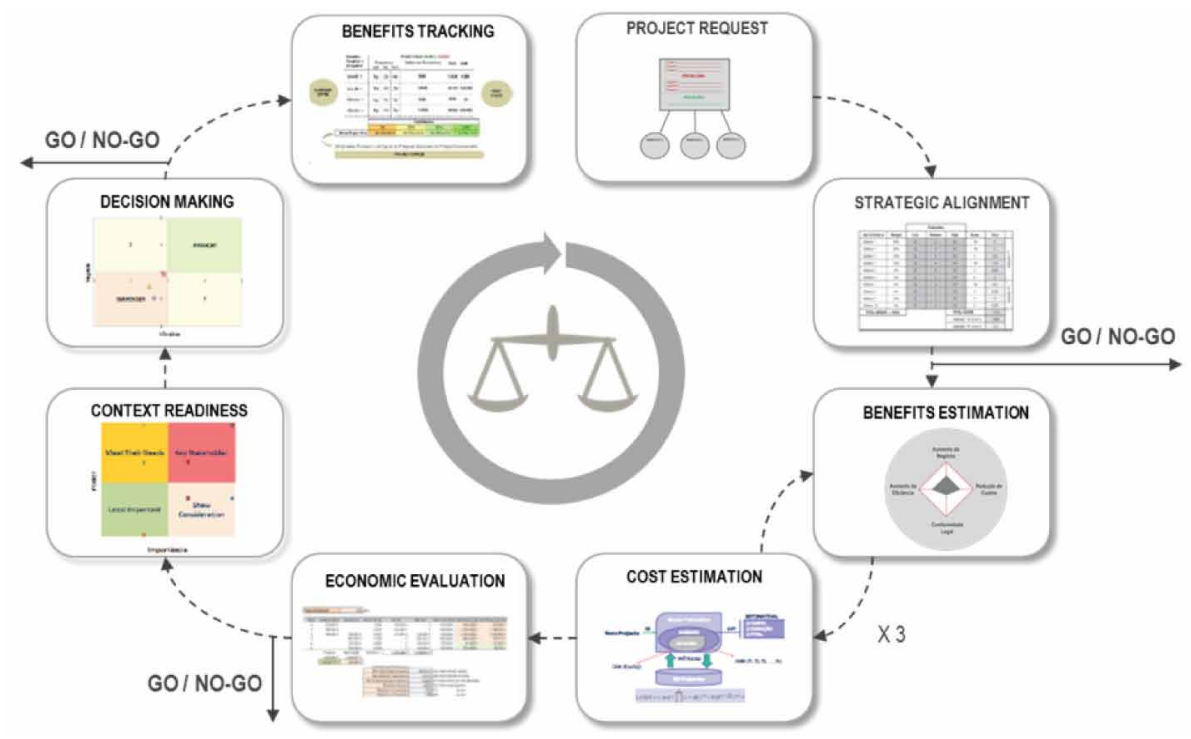


the outputs generated in each step. These steps are sequential which means that in order to move a step forward in the process it is required to have the previous step duly completed.

Once completed these 8 steps a final decision has been made. The output provided by this framework is based in all the studies and conclusions made both for consultation in the benefits measurement phase as well as for historical records purposes. The result of the Decision-Making process relies on deciding whether to implement the initiative, after the analysis pursued in the previous steps, namely the economic, financial and context analysis has been fully analysed. Based on this information, reliable sources and accurate data, along with the financial models that allow the sensitivity analysis and interaction scenarios, the board of directors (decision-makers) are able to make a more confident decision based on evidences about the feasibility in the investment.

\section{BC Tool}

The Business Case Tool (BC Tool) is a tool that uses different algorithms and methods to support and choose the best investment decision based in several outputs provided by the conjunction of different inputs and tools \& techniques (table 1), rather than relying only on traditional evidence and methods like ROI calculation it allows also the use of other metrics, for instance SROI. It uses Machine Learning (ML) algorithms. This tool was developed in order to verify the economic and financial viability of an investment initiative in a company / organization.

Given the current context of high market competitiveness, the need to rationalize economic, financial, human resources or the introduction of a new product on the market requires the development of a business case that will allow it to investigate whether this initiative is strategic and generate wealth for the company / organization. These objectives are applied to several issues and, therefore, the development of a Business Case application, oriented to project management, at the level of good practices and that contemplates a diversity of models and statistical algorithms is an added value to the needs of the the market and the lack of adequate solutions that allow a transformation of information of a high degree of confidence.

One of the strengths of this tool is the fact that it doesn't have only a scientific component but also a business overview which provide a technical capability to measure the benefits estimation.

The description of each step of the BC Tool is based in the BcBOK (2015). As mentioned previously, the $\mathrm{BC}$ Tool have 8 main steps:

- Project Request: The project request process aims to formalise the initiative request in a standard way. It is essential that it clearly establishes the current envisioned problem, highlight the negative impacts caused to the organisation, as well as what is aimed to obtain in the future while never forgetting to mention the impact of not doing it and identify what are the benefits leveraged by the solution proposed. It shall also formulate a high-level impact analysis in the company architecture: functional areas, processes and systems.

- Strategic Alignment: The Strategic Alignment process aims to qualitatively assess whether a particular initiative has the minimum conditions to move forward in evaluation process. The goal is to understand how much the initiative is strategic to be considered as a potential investment. The model should consider the possibility of exceptions and allow an effective reading in senior management language of the organisation.

- Benefits Estimation: The process of Benefit Estimation aims to assess the impact of project benefits quantitatively in the business and in the company. Benefits are measurable and perceived value improvements by one or more stakeholders (Sanchez et al., 2010).

- Cost Estimation: The Cost Estimation process aims to get a cost estimate for the project. This estimate should include not only the cost of the project but also the new operational costs. The product components should be addressed as well as the uncertainty of the project for which the estimate is conservative to ensure that the budget available is sufficient. In extreme situations cost options might also be considered to evaluate alternative scenarios. 
Table 1. BC Tool Structure (Source: BcBOK, 2015)

\begin{tabular}{|c|c|c|c|}
\hline Business Case Steps & 1. Inputs & 2. Tools and Techniques & 3. Outputs \\
\hline Project Request & $\begin{array}{l}.1 \text { Strategic Plan } \\
.2 \text { Market Demand } \\
.3 \text { Legal Requirement } \\
.4 \text { Client Request } \\
.5 \text { Innovation Initiative } \\
.6 \text { Technological Advance } \\
.7 \text { Request for Bid } \\
.8 \text { Enterprise Reports } \\
.9 \text { Enterprise Risk }\end{array}$ & $\begin{array}{l}.1 \text { Problem-Solving } \\
.2 \text { Elevator Pitch } \\
.3 \text { POLDAT } \\
.4 \text { Futures Wheel } \\
.5 \text { ZACHMAN } \\
.6 \text { Expert Judgment } \\
.7 \text { Enterprise Workflow } \\
.8 \text { Enterprise Architecture } \\
.9 \text { Business Requirement }\end{array}$ & .1 Project Request Form \\
\hline Strategic Alignment & $\begin{array}{l}.1 \text { Project Request Form } \\
.2 \text { Strategic Plan } \\
.3 \text { Organisation Capacity } \\
.4 \text { Exceptional Conditions }\end{array}$ & $\begin{array}{l}.1 \text { Strategic Force Analysis } \\
.2 \text { Scoring Model } \\
.3 \text { Murder Board } \\
.4 \text { SWOT Analysis } \\
.5 \text { Peer Review } \\
.6 \text { Nominal Group } \\
.7 \text { Delphi Technique } \\
.8 \text { Paired Comparison Analysis } \\
.9 \text { Analytical Hierarchy Process }\end{array}$ & $\begin{array}{l}.1 \text { Strategic Alignment } \\
.2 \mathrm{Go} / \mathrm{No}-\mathrm{Go}\end{array}$ \\
\hline Benefits Estimation & $\begin{array}{l}.1 \text { Project Request Form } \\
.2 \text { Strategic Alignment } \\
.3 \text { Enterprise Environment Factors } \\
.4 \text { Outer Context } \\
.5 \text { Historical Data } \\
.6 \text { Market Reports }\end{array}$ & $\begin{array}{l}.1 \text { Data Collection Plan } \\
.2 \text { Pareto Analysis } \\
.3 \text { Gap Analysis } \\
.4 \text { Parametric Analysis } \\
.5 \text { Control Group } \\
.6 \text { Focus Group } \\
.7 \text { Prototyping } \\
.8 \text { Simulation } \\
.9 \text { Survey's } \\
.10 \text { Three Point Estimate } \\
.11 \text { Sensitive Analysis }\end{array}$ & $\begin{array}{l}.1 \text { Benefits Plan } \\
.2 \text { Benefits Estimation } \\
.3 \text { Benefits Sensitive Data }\end{array}$ \\
\hline Cost Estimation & $\begin{array}{l}.1 \text { Project Request Form } \\
.2 \text { Benefits Estimation } \\
.3 \text { Enterprise Environment Factors } \\
.4 \text { Outer Context } \\
.5 \text { Historical Data } \\
.6 \text { Market Reports }\end{array}$ & $\begin{array}{l}.1 \text { Product Breakdown Structure } \\
.2 \text { Parametric Analysis } \\
.3 \text { Analogous Estimation } \\
.4 \text { Bottom-Up Estimation } \\
.5 \text { Cost Breakdown Structure } \\
.6 \text { Expert Judgment } \\
.7 \text { Risk Register } \\
.8 \text { Three Point Estimate } \\
.9 \text { Sensitive Analysis }\end{array}$ & $\begin{array}{l}.1 \text { Cost Estimation } \\
.2 \text { Costs Sensitive Data }\end{array}$ \\
\hline Economic Evaluation & $\begin{array}{l}.1 \text { Benefits Estimation } \\
.2 \text { Cost Estimation } \\
.3 \text { Benefits Sensitive Data } \\
.4 \text { Costs Sensitive Data }\end{array}$ & $\begin{array}{l}.1 \text { Economic-Financial Analysis } \\
\text { (NPV, BCR, ERR, ROI, PAYBACK) } \\
.2 \text { Interest Rate } \\
.3 \text { ROI Sensitive \& Risk Analysis } \\
.4 \text { Profit \& Lost Planning }\end{array}$ & $\begin{array}{l}.1 \text { Economic-Financial Indicators } \\
.2 \text { ROI Sensitive Data } \\
.3 \text { Benefits \& Cost Plan } \\
.4 \mathrm{Go} / \text { No-Go }\end{array}$ \\
\hline Context Readiness & $\begin{array}{l}.1 \text { Project Request Form } \\
.2 \text { Enterprise Architecture } \\
.3 \text { Strategic Alignment } \\
.4 \text { ROI Sensitive Data } \\
.5 \text { Enterprise Environment Factors }\end{array}$ & $\begin{array}{l}.1 \text { Stakeholder Matrix } \\
.2 \text { Force Field Analysis } \\
.3 \text { Expert Judgment } \\
.4 \text { Climate Analysis }\end{array}$ & $\begin{array}{l}.1 \text { Context Analysis } \\
.2 \text { Stakeholders Analysis }\end{array}$ \\
\hline Decision Making & $\begin{array}{l}.1 \text { Project Request Form } \\
.2 \text { Enterprise Architecture } \\
.3 \text { Strategic Alignment } \\
.4 \text { Benefits Estimation } \\
.5 \text { Cost Estimation } \\
.6 \text { ROI Sensitive Data } \\
.7 \text { Context Analysis } \\
.8 \text { Enterprise Environment Factors }\end{array}$ & $\begin{array}{l}.1 \text { SWOT Analysis } \\
.2 \text { Business Case Canvas } \\
.3 \text { Nominal Group } \\
.4 \text { Multi-Criteria Scenarios } \\
.5 \text { Expert Judgment } \\
.6 \text { Delphi Technique }\end{array}$ & $\begin{array}{l}.1 \text { Business Case Report } \\
.2 \text { Go/No-Go }\end{array}$ \\
\hline Benefits Tracking & $\begin{array}{l}.1 \text { Benefits Plan } \\
.2 \text { Business Case Report }\end{array}$ & $\begin{array}{l}.1 \text { Corporate Reports } \\
.2 \text { Trend Analysis } \\
.3 \text { Balanced Scorecard } \\
.4 \text { Control Group }\end{array}$ & $\begin{array}{l}.1 \text { Benefits Tracking Report } \\
.2 \text { New Opportunities }\end{array}$ \\
\hline
\end{tabular}

- Economic Evaluation: The economic assessment process aims to calculate whether the initiative is economically interesting for the organisation. The underlying principle in the worst case, the initiative should be profitable and pursue the goal of a minimum 50\% ROI. The decision about a project moving forward or not, should always consider a minimum trust level from $80 \%$ to $95 \%$ in the combined cost and benefit cash flows. 
- Context Readiness: The Context Readiness process aims to evaluate whether the company and the market are prepared to accommodate the project. This analysis aims to capture the internal and external environment as well as the supporters and opponents of the initiative before making a final decision. Many organisations evaluate projects that economically are of high value but find that they are not prepared to welcome them, because culture, maturity or vested interests are not a suitable habitat.

- Decision Making: The Decision-Making Process aims to gather all the information and helps senior management to make the decision. There are four mandatory elements to consider in the decision matrix: the initiative strategic alignment, the benefits, the investment and the internal and external climate in relation to the project. Both the benefit and the investment should consider the uncertainty involved and therefore the decision should be made within a conservative scenario.

- Benefits Measurement: The process of Benefits Tracking aims to measure the Business Case during the product, service or process exploitation period. This step is of high value as it allows the organisation to not only measure the quality of the investment in the decision-making process, as well as identify new investment opportunities to add continuous value to the organisation.

\section{METHODOLOGY}

The initiative of the benefits for the Intervention Plan for the reduction of hypertension is based on a set of actions aimed at a gradual change in the eating habits of the elderly under observation, measure their contribution to their quality of life. These actions are the kernel for the project implementation which will contribute to the health improvement and quality of life of the Foundation patients. Among these actions, based in Trieu et al., 2015, the following one have been selected: Food reformulation, targets for salt levels in food, consumer behavior, labelling and defined policy from public institutions (Portuguese Intervention Plan for the reduction of hypertension) besides employees formation (knowledge gain and behavior validation while cooking). These actions are not possible to be quantified in terms of number although these actions will provide the measurements benefits which will be analyzed in the results section.

Regarding this Business Case, this measurement was made in the Foundation Sarah Beirão. This foundation intends to provide a social response to elderly people, contributing to the personal valorization and sharing of knowledge, providing during the day the resolution of basic needs. This sample for healthcare studies increase the content validity and generalizability (Eisenhardt, 1989). The sample data were 70 elderly, 45 women and 25 men with an average age more than 65 years old.

The quantification of benefits of these actions through project implementation were calculated based on an experimental group of users from the Sarah Beirão Foundation, who were subject to a change in the diet plan according the proposed actions. The benefits measurement where then applied to the sample data.

This methodology aims to measure the benefits from intangible and tangible features (figure 2). To achieve this measurement, it has been used the BC Tool framework and the 8 steps in order to accomplish a proper benefit measurement. The benefits obtained from the tangible features are crucial to the SROI measurement.

The data has been collected during the months of February and March of 2019. This time range is considered appropriate for measurement the benefits of reduction in medication, increase the quality of life and satisfaction by family members. This period is related with the entrance of the newcomers which occurs in January. Since this Foundation has a specific period to the newcomers entry and contract arrangement. The months of February and March are the months immediately after the entrance and feasible to be measured and provide a crucial feedback.

The reliability of the findings was ensured by drawing data from appropriate sources. It has been made in-depth interviews with multiple respondents (patients and family members). The questionnaire, based in open questions, was divided into 4 groups (Communication, Foundation Improvements, 


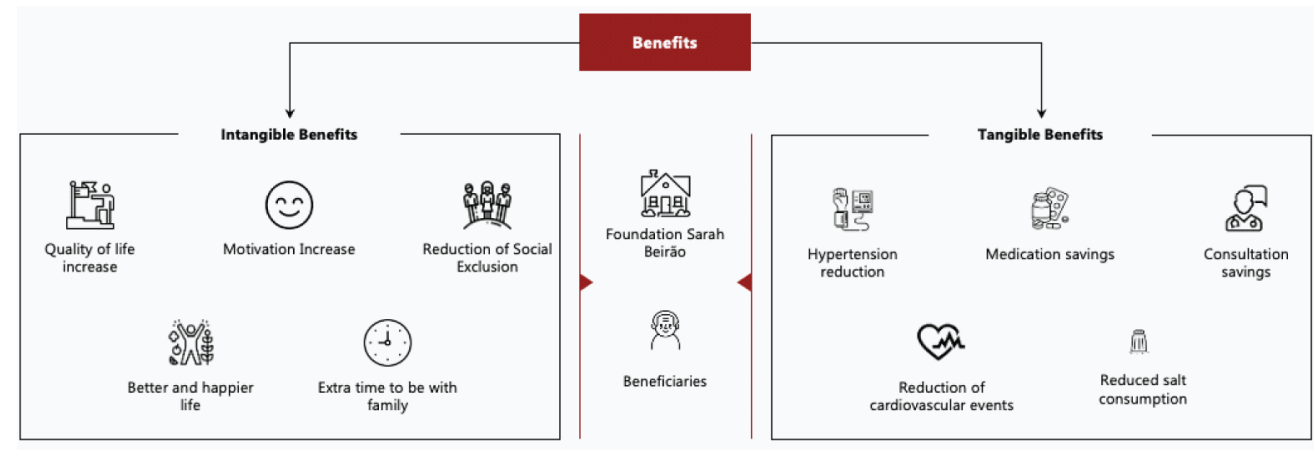

Workers and Financial). A total of 10 questions have been made and are described in table 2. These questions aim to evaluate the perception of the patients and how it can influence the actions for the hypertension reduction.

\section{RESULTS}

The obtained results from the BCTool allowed to measure several parameters as mentioned previously. This results aims to validate if the proposed plan to reduce the hypertension is translated in a benefit for the Foundation (tangible benefits) and quality of life from the patients (intangible benefits). In the next section these results are explained in detail in order to provide an output for the Business Case results.

\section{Benefits Measurements}

The measurement of the direct benefits make it possible to have a sense of the effect from social intervention thus, it is necessary to clearly understand which methodology is used in this particular case, as well as what are the expected values of the intervention in different scenarios, such as the pessimistic, more likely and optimistic.

The Pessimistic and Optimistic cost was calculated based on a variation of $-5 \%$ and $+5 \%$ compared to the most likely value. It is considered as a benefit for users not to spend on cardiology consultations ( $€ 37.97$ per consultation) and savings on medication costs ( $€ 8.65$ per daily medication). Savings in medication costs ( $€ 9.92$ per daily medication) and a reduction in hospitalizations due to stroke resulting from hypertension ( $€ 1,721$ per hospitalization episode) are considered as benefits for the State. Around $53 \%$ of benefits refer to the State, with the remaining $47 \%$ corresponding to users. The results from these three scenarios are presented in figure 3.

To quantify accurately all of the direct benefits and with a certain grade of accuracy, it was necessary to quantify numerically all the key expected benefits of the initiative. We use a conservative approach to estimate all the benefits, using a three-point estimate. The three-point estimation technique is used in management and information systems applications for the construction of an approximate probability distribution representing the outcome of future events, based on very limited information, which is normally the case we face. While the distribution used for the approximation might be a normal distribution, this is not always so and, for example a triangular distribution might be used, depending on the application. In three-point estimation, three figures are produced initially for every distribution that is required, based on prior experience or best-guesses: (i) $\mathrm{a}=$ the best-case estimate; (ii) $\mathrm{m}=$ the most likely estimate; (iii) $\mathrm{b}=$ the worst-case estimate. These are then combined to yield either a full probability distribution, for later combination with distributions obtained similarly for 
Table 2. Questionnaire

\begin{tabular}{|c|c|}
\hline ID & Question \\
\hline 1 & $\begin{array}{l}\text { What is the impact / role of the Sarah Beirão Foundation in } \\
\text { the community? What about family members? }\end{array}$ \\
\hline 2 & $\begin{array}{l}\text { Why did you choose the Foundation to welcome your family } \\
\text { member? }\end{array}$ \\
\hline 3 & $\begin{array}{l}\text { What are the main pains / needs you encounter in relation to } \\
\text { your family member? }\end{array}$ \\
\hline 4 & $\begin{array}{l}\text { What is the main form of communication with the } \\
\text { Foundation? }\end{array}$ \\
\hline 5 & $\begin{array}{l}\text { What knowledge do you have about this initiative? What } \\
\text { importance does it give you? }\end{array}$ \\
\hline 6 & $\begin{array}{l}\text { Have you ever been given information (inside or outside the } \\
\text { Foundation) about the importance of eating habits? }\end{array}$ \\
\hline 7 & $\begin{array}{l}\text { How much do you think the Foundation spends on health } \\
\text { care? Does it seem fair? What about what you pay for the } \\
\text { services provided? }\end{array}$ \\
\hline 8 & $\begin{array}{l}\text { Do you think the Foundation has a disciplined team with } \\
\text { know-how in relation to these and other geriatric health } \\
\text { actions? }\end{array}$ \\
\hline 9 & $\begin{array}{l}\text { In practical terms, what do you think are the main } \\
\text { challenges and changes after its implementation? What } \\
\text { suggestions would you give to your process? }\end{array}$ \\
\hline 10 & $\begin{array}{l}\text { What do you hope this initiative will bring to the } \\
\text { Foundation and users in the medium, long term? }\end{array}$ \\
\hline
\end{tabular}

Figure 3. Direct Benefits Scenarios

$\frac{391.997 €}{\text { Pessimist }} \quad \frac{411.597 €}{\text { More Likely }} \frac{432.177 €}{\text { Optimistic }}$
$\begin{gathered}\text { Total } \\ \text { Average of the Benefits: } 411.760,05 € \\ \text { Variance: } 44.844 .628,62 € \\ \text { Standard Deviation: } 6.696,61 €\end{gathered}$

other variables, or summary descriptors of the distribution, such as the mean, standard deviation or percentage points of the distribution. The accuracy attributed to the results derived can be no better than the accuracy inherent in the 3 initial points, and there are clear dangers in using an assumed form for an underlying distribution that itself has little basis. In this practical application of the three-point estimate, through the obtained results () it is possible to verify that for a level of confidence between $80 \%$ and $95 \%$ the variation of the benefits value is reduced (less than $5,378 €$ or less than $1,34 \%$ ). It is also relevant to note that $53 \%$ of the forecasted benefits will be those of the Portuguese State, 
Table 3. Benefits Quantification

\begin{tabular}{|c|c|c|}
\hline Risk & Benefits & Level of Confidance \\
\hline $1 \%$ & $396181,40 €$ & $\mathbf{9 9 \%}$ \\
\hline $5 \%$ & $400745,10 €$ & $\mathbf{9 5 \%}$ \\
\hline $10 \%$ & $403177,99 €$ & $\mathbf{9 0 \%}$ \\
\hline $15 \%$ & $404819,45 €$ & $85 \%$ \\
\hline $20 \%$ & $406124,04 €$ & $80 \%$ \\
\hline $25 \%$ & $407243,25 €$ & $75 \%$ \\
\hline $30 \%$ & $408248,34 €$ & $70 \%$ \\
\hline $35 \%$ & $409179,70 €$ & $65 \%$ \\
\hline $40 \%$ & $410063,48 €$ & $60 \%$ \\
\hline $45 \%$ & $410918,54 €$ & $\mathbf{5 5} \%$ \\
\hline $\mathbf{5 0} \%$ & $411760,05 €$ & $\mathbf{5 0} \%$ \\
\hline $55 \%$ & $412601,55 €$ & $45 \%$ \\
\hline $60 \%$ & $413456,61 €$ & $40 \%$ \\
\hline $65 \%$ & $414340,39 €$ & $35 \%$ \\
\hline $70 \%$ & $415271,75 €$ & $\mathbf{3 0} \%$ \\
\hline $75 \%$ & $416276,84 €$ & $25 \%$ \\
\hline $80 \%$ & $417396,06 €$ & $20 \%$ \\
\hline $85 \%$ & $418700,64 €$ & $15 \%$ \\
\hline $90 \%$ & $420342,10 €$ & $10 \%$ \\
\hline $95 \%$ & $422775,00 €$ & $5 \%$ \\
\hline $99 \%$ & $427338,70 €$ & $1 \%$ \\
\hline
\end{tabular}

while the remaining $47 \%$ benefits will affect the direct beneficiaries and their families in terms of medical care and healthcare treatments.

In the Figure 4 is represented the evolution of the benefits for each confidence level presented in . It is also relevant to note that $53 \%$ of all the forecasted benefits will be for the Portuguese State, while the remaining $47 \%$ benefits will be for the direct beneficiaries and their families.

\section{Cost Analysis}

For a viable cost analysis to be carried out, it is necessary that all the assumptions - whether predefined or calculated - necessary for calculating the costs, as well as the reason for their existence. The costs have been divided into three groups, the Human Resources, Medical Equipment and Others. Equal as Benefits measurement, the Cost Analysis has been divided into three groups (Pessimistic, More Likely and Optimist). The pessimistic and optimistic values were considered to be the result of a variation of $-5 \%$ and $+5 \%$ respectively compared to the most likely value (Figure 5).

The cost with human resources includes 1 Nutritionist, 1 Administrative, 4 Nurses (part-time), 4 Doctors (part-time) and 4 Physiotherapists (part-time); Medical equipment costs include all costs of acquisition of this type of equipment and Other costs refer to expenses with computers, software, analysis and miscellaneous expenses.

It is also relevant to note that the costs are above $€ 300,000.00$ of available financing, negatively impacting the value of the SROI. The cost difference is assumed by the Sarah Beirão Foundation. 
Figure 4. Benefit S-Curve

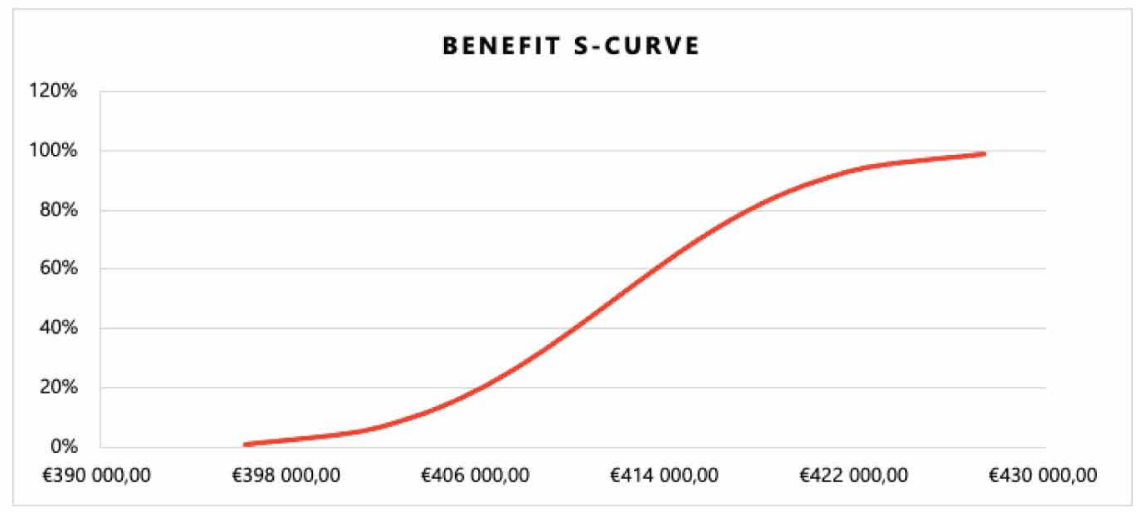

Figure 5. Cost Analysis Scenario

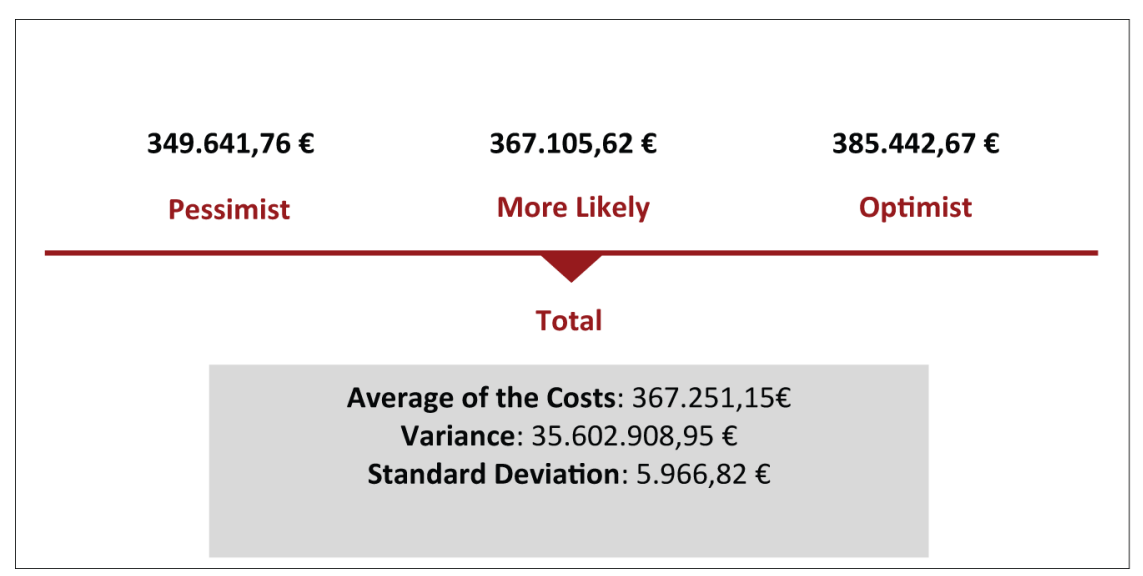

Similarly to the benefits estimation, we also used the three-point estimation for Costs. The resulting curve on Costs were evaluated from an S-curve point of view (Figure 6), since it allows a reduction in the margin of errors, allowing for a forecast and anticipation of unforeseen events through a comparison of current results with the predicted results. Again, similarly to the Benefits estimation, we use the conservative approach for Costs estimation, with confidence levels between 80 and $95 \%$.

Similarly, to the Benefits and Costs estimation, it was used the three-point estimation of SROI, as it is a formula resulting directly from Benefits and Costs. Through the obtained results in table 4 it is possible to verify that for a level of confidence between $80 \%$ and $95 \%$, the variation is reduced $(4,792.74 €)$. Regarding to the Benefits and Costs estimations, it has been used the conservative approach for SROI estimation, with confidence levels between 80 and $95 \%$.

\section{SROI}

In order to scientifically assess the SROI, it is important to understand the principles inherent to its methodology, as well as to ensure that the collection of data necessary for its calculation comes from interested parties directly related to the initiative. When both benefits and costs are calculated, it is 
Figure 6. Cost S-Curve

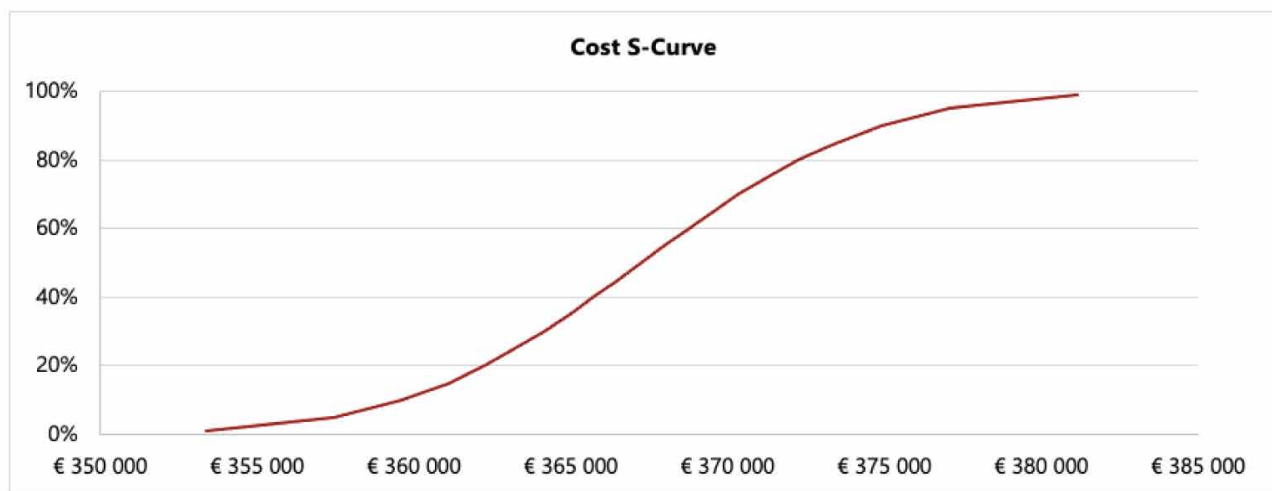

Table 4. Cost Analysis Quantification

\begin{tabular}{|c|c|}
\hline Level of Confidance (\%) & Value $(€)$ \\
\hline $99 \%$ & $381132,04 €$ \\
\hline $95 \%$ & $377065,69 €$ \\
\hline $90 \%$ & $374897,93 €$ \\
\hline $85 \%$ & $373435,36 €$ \\
\hline $80 \%$ & $372272,95 €$ \\
\hline $75 \%$ & $371275,71 €$ \\
\hline $\mathbf{7 0} \%$ & $370380,15 €$ \\
\hline $65 \%$ & $369550,29 €$ \\
\hline $60 \%$ & $368762,83 €$ \\
\hline $55 \%$ & $368000,95 €$ \\
\hline $\mathbf{5 0} \%$ & $367251,15 €$ \\
\hline $45 \%$ & $366501,35 €$ \\
\hline $40 \%$ & $365739,47 €$ \\
\hline $35 \%$ & $364952,01 €$ \\
\hline $30 \%$ & $364122,15 €$ \\
\hline $25 \%$ & $363226,59 €$ \\
\hline $20 \%$ & $362229,35 €$ \\
\hline $15 \%$ & $361066,94 €$ \\
\hline $10 \%$ & $359604,37 €$ \\
\hline $5 \%$ & $357436,61 €$ \\
\hline $1 \%$ & $353370,26 €$ \\
\hline
\end{tabular}


Table 5. SROI Quantification

\begin{tabular}{|l|l|l|l|}
\hline \multicolumn{1}{|c|}{ Level of Confidence (\%) } & \multicolumn{1}{|c|}{ Cost $€$} & \multicolumn{1}{c|}{ Benefits } & \multicolumn{1}{c|}{ SROI } \\
\hline $\mathbf{9 9} \%$ & $381132 €$ & $396181 €$ & $\mathbf{1 , 0 4}$ \\
\hline $\mathbf{9 5} \%$ & $377066 €$ & $400745 €$ & $\mathbf{1 , 0 6}$ \\
\hline $\mathbf{9 0} \%$ & $374898 €$ & $403178 €$ & $\mathbf{1 , 0 8}$ \\
\hline $\mathbf{8 5} \%$ & $373435 €$ & $404819 €$ & $\mathbf{1 , 0 8}$ \\
\hline $\mathbf{8 0} \%$ & $372273 €$ & $406124 €$ & $\mathbf{1 , 0 9}$ \\
\hline $\mathbf{7 5} \%$ & $371276 €$ & $407243 €$ & $\mathbf{1 , 1 0}$ \\
\hline
\end{tabular}

important to verify the SROI from social intervention. In this way, it will be possible to perceive the social value derived from the initiative "Intervention plan to reduce hypertension".

The values presented in Table 5 are related with the overall benefits measurements from the tangible benefits, namely the Benefits quantification (), Cost analysis quantification (table 4) plus the SROI which is the result from the Cost and Benefits. The SROI ratio obtained by the intervention "Intervention plan for the reduction of hypertension" assumes a value of 1.06 with a $95 \%$ confidence level (table 5). This value means that for every euro invested in the intervention, it generates a return of $€ 1.06$ in social value (figure 7 ).

Figure 7. SROI S-Curve

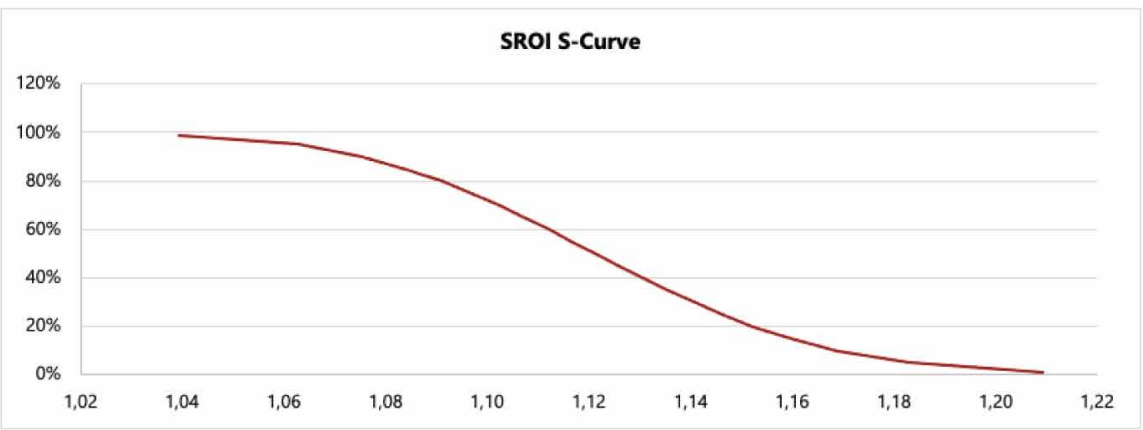

\section{Questionnaires Replies}

The aim of the questionnaire was to evaluate the replies from the patients foundation in order to have a perception if the actions which would be implemented will be crucial for the hypertension reduction. Although the Benefits and Costs aim to provide a quantitative measure which was considerable successful due to the Benefits, Cost and SROI results the questionnaire provided an useful feedback regarding the patient perception. The replies to the questionnaire Regarding the suggestions mentioned it has been point out the following: More communication on possible important aspects (e.g. initiatives to be developed) Inform about the development of the initiative (e.g. What is being done, what results have been obtained, ...); In terms of work, the patients mention that the workers should have, in general, more training in terms of healthcare and should have more employees to respond to user needs. Several of the interviewed family members noticed a visible work overload on the part of the employees, thus preventing a more specialized monitoring of the users. Regarding 
the improvements of the foundation, the patients have identified several advancement for improving the foundation quality, namely more activities to minimize excess downtime, more personalized monitoring of users with reduced mobility, for example, having more time with users in the outer space, visit time extension and creation of an alternative space to the common room, where users who want to perform activities that involve more concentration (e.g. painting, reading ...) can be without so many distractions. At least, in terms of financial analysis, the patient's relatives believe they are paying a fair amount, they would like more support such as Social Security.

Regarding the other question replies from the results is clearly demonstrated the motivation from the patients regarding the implementation of this plan. The motivation and will of adopting a life style which can produce a better quality of life was a key asset for the success of this initiative which lead to a considerable increase in the benefits, cost reduction and SROI positive. The satisfaction from the patients with the foundation was another important milestone for the success of the project implementation.

\section{CONCLUSION}

This paper has contributed to the initiative "Intervention Plan for the reduction of hypertension". This initiative aims to reduce the high salt consumption in Portugal, namely in foundation where the average age is 65 years old. In this sense, the initiative proposes to reduce the consumption of salt, improving the control of HTN through a phased reduction of salt which will be measured in terms of social benefits, health and economic savings.

The Business Case analysis has proved an added valuable tool since it allows a considerable benefit for the foundation. Besides the measurement benefits this work allowed to collect several inputs as added value for several different fields, such as communication, the foundation itself, workers and financial status. These inputs aim to increase the level of efficiency of these services and provide a considerable increase of the provided services.

In terms of benefits, the adoption of the BC Tool allowed to extract several intangible and tangible benefits related with business growth, efficiency increase or cost reduction since they are expressed differently over time. Thus, it allows an Efficiency Increase, typically has a medium / long term effect, since once it gets into the operation period the impact in the organisation takes some time to stabilise.

Since this work involved people and require their commitment to achieve success, it is important to consider their learning curve and their expectations / perceptions. In general, people move from a state of pessimistic-optimistic-realistic or, reversely, optimistic-pessimistic-realistic. At the time it is reported, the introduction of the new project and consequently organisational change, people's reaction may take one of two forms: refusal or acceptance; pessimism over the project contribution or optimistic over the expected results foreseen. However, often over time, the behaviour changes to the opposite, to a state of amazement or disappointment, accordingly. Therefore, it is suggested that the benefits measurement occurs at least after three months. A single measurement may be done, as after stabilising it is unlikely that the benefits will change, however a new measurement may be made, in order to confirm and review the baseline

The Costs Reduction benefit, it is essential to start from identifying what cost items will be affected with the project implementation and when this is expected. It's important to analyse that projects aiming for cost reduction might result in an immediate reduction, for example, changing the organisation's premises to a location with a lower rent or a gradual reduction - for example, the gradual renewal of the car fleet to more fuel-efficient vehicles. Depending on when the benefit is carried out, the time frame to measure the benefits must be adapted accordingly.

In the end, this work allowed to reduce the HTA in the patients at Foundation Sarah Beirão which was measured but the increasing benefits presented in the , 4 and 5 . The reduction has obtained by adopting the Food reformulation, targets for salt levels in food, consumer behavior, labelling and 
defined policy from public institutions (Portuguese Intervention Plan for the reduction of hypertension) as mentioned in the methodology.

\section{FUTURE WORK}

After the development and implementation of a prototype to test a final solution, a methodology is defined for the implementation script for the final solution, with the objectives of training the entity and applying the SROI calculation methodology to other IIES of the organization, current or future as described in figure 8 .

Figure 8. Roadmap and future work

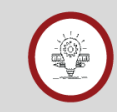

Prototype Development

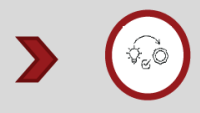

Prototype Implementaton

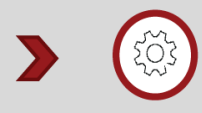

Application

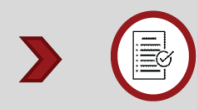

Validation

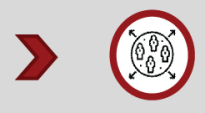

Entity Training

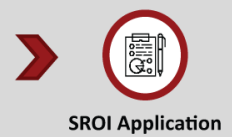

This work could also be extended to the all foundation available in the municipality. It is important to analyze and understand the impact of this initiative, if it were implemented throughout the municipality of Tábua, in order to understand the feasibility of extending the initiative to all the elderly in the municipality. Through the analysis of benefits carried out, it is concluded that, if the initiative "Intervention Plan for the Reduction of Hypertension" covers all the elderly hypertensive patients in the municipality of Tábua, the State could save 1,917,642 € (savings on medication costs). Thus, the adoption of this methodology to other geographical range and different municipalities and taking into account the concept of linearity, will provide greater savings for the foundations and lower incidence rate of arterial HTA in the Portuguese population.

\section{LIMITATION OF THE STUDY}

This work suffers for some limitations although is technical and theoretical contribution for the Business Case. The main limitation is the sample, since is limited. Thus, future research might test the BC Tool methodology on a wider number of organizations from the same municipality of different geographic areas.

The Business Case methodology lack from additional modules, for instance Time Series Analysis which could allow a future projection based in this analysis.

\section{ACKNOWLEDGMENT}

This article is a result of the project BC Tool.: Business Case Tool: Benefits Management (LISBOA01-0247-FEDER-038522), supported by Lisbon Portugal Regional Operational Programme (LISBOA 2020), under the PORTUGAL 2020 Partnership Agreement, through the European Regional Development Fund (ERDF)". 


\section{REFERENCES}

Alawwa, I., Dagash, R., Saleh, A., \& Ahmad, A. (2018). Dietary salt consumption and the knowledge, attitudes and behavior of healthy adults: A cross-sectional study from Jordan. The Libyan Journal of Medicine, 13(1).

Alwan, A. (2011). Global status report on noncommunicable diseases 2010. World Health Organization.

Association for Project Management. (2019). APM Body of Knowledge (7th ed.). Association for Project Management.

Baker, E. L., Brand, W., Davidson, A., LaVenture, M., Singletary, V., \& Smith, P. (2016). Building the business case for public health information systems. Journal of Public Health Management and Practice, 22(6), $603-606$. doi:10.1097/PHH.0000000000000495 PMID:27682729

BCBOK®. (2015). A Guide to the Business Case Body of Knowledge (2 $2^{\text {nd }}$ ed.). Business Case Institute.

Cappuccio, F. P. (2013). Cardiovascular and other effects of salt consumption. Kidney International. Supplement, $3(4), 312-315$.

Charles, J. M., Jones, A., \& Lloyd-Williams, H. (2019). Return on investment, social return on investment, and the business case for prevention. Applied Health Economics for Public Health Practice and Research, 279.

Chin, M. H. (2016). Creating the business case for achieving health equity. Journal of General Internal Medicine, 31(7), 792-796.

Einhorn, F., Marnewick, C., \& Meredith, J. (2019). Achieving strategic benefits from business IT projects: The critical importance of using the business case across the entire project lifetime. International Journal of Project Management, 37, 989-1002.

Eisenhardt, K. M. (1989). Building theories from case study research. Academy of Management Review, 14(4), 532-550.

Fischer, H. R., \& Duncan, S. D. (2020). The business case for quality improvement. Journal of Perinatology, 1-8.

Garrido, T., Raymond, B., Jamieson, L., Liang, L., \& Wiesenthal, A. (2004). Making the business case for hospital information systems - a Kaiser Permanente investment decision. Journal of Health Care Finance, 31(2), 16-25.

Gomes, J. F., Kemppainen, L., Pikkarainen, M., Koivumäki, T., \& Ahokangas, P. (2019). Ecosystemic business model scenarios for Connected Health. Journal of Business Models, 7(4), 27-33.

Gosselin, V., Boccanfuso, D., \& Laberge, S. (2020). Social return on investment (SROI) method to evaluate physical activity and sport interventions: A systematic review. The International Journal of Behavioral Nutrition and Physical Activity, 17(1), 1-11.

Ha, S. K. (2014). Dietary salt intake and hypertension. Electrolytes \& Blood Pressure. E \& BP, $12(1), 7$.

Luck, J., Parkerton, P., \& Hagigi, F. (2007). What is the business case for improving care for patients with complex conditions? Journal of General Internal Medicine, 22(3), 396-402.

Merino, M., Jiménez, M., Manito, N., Casariego, E., Ivanova, Y., González-Domínguez, A., \& Blanch, C. et al. (2020). The social return on investment of a new approach to heart failure in the Spanish National Health System. ESC Heart Failure, 7(1), 131-138.

Nicholls, J. (2017). Social return on investment-Development and convergence. Evaluation and Program Planning, 64, 127-135.

Olsson, N. O. E. (2018). Elaborations on the role of project owner: Introducing project owners type 1 and 2. International Journal of Managing Projects in Business, 11, 827-844.

Palmer, N., \& Mooney, L. (2009). Building a Business Case for BPM-a Fast Path to Real Results. Academic Press.

Sadler, B. L., DuBose, J., \& Zimring, C. (2008). The business case for building better hospitals through evidencebased design. HERD: Health Environments Research \& Design Journal, 1(3), 22-39.

Sanchez, H., \& Robert, B. (2010). Measuring portfolio strategic performance using key performance indicators. Project Management Journal, 41(5), 64-73. 
Shanafelt, T., Goh, J., \& Sinsky, C. (2017). The Business Case for Investing in Physician Well-being. JAMA Internal Medicine, 177(12), 1826.

Singh, J. A., \& Yu, S. (2016). Emergency department and inpatient healthcare utilization due to hypertension. BMC Health Services Research, 16(1), 303.

Trieu, K., Neal, B., Hawkes, C., Dunford, E., Campbell, N., Rodriguez-Fernandez, R., Legetic, B., McLaren, L., Barberio, A., \& Webster, J. (2015). Salt reduction initiatives around the world-a systematic review of progress towards the global target. PLoS One, 10(7), e0130247.

Turner, B. J., Hollenbeak, C. S., Weiner, M., Ten Have, T., \& Tang, S. S. (2008). Effect of unrelated comorbid conditions on hypertension management. Annals of Internal Medicine, 148(8), 578-586.

UK Cabinet Office. (2012). A Guide to Social Return on Investment. Author.

Ward, J., Daniel, E., \& Peppard, J. (2008). Building better business cases for IT investments. MIS Quarterly Executive, 7, 1-15.

World Health Organization. (2007). Reducing salt intake in populations: report of a WHO forum and technical meeting, 5-7 October 2006, Paris, France. WHO.

World Health Organization. (2014). Global status report on noncommunicable diseases 2014 (No. WHO/NMH/ NVI/15.1). World Health Organization.

Zwetsloot, G. I. J. M., \& Van Scheppingen, A. (2007). Towards a strategic business case for health management. Thomson Fakta.

Zwikael, Chih, Y.-Y., \& Meredith, J. (2018). Project benefit management: Setting effective target benefits. International Journal of Project Management, 36, 650-658. 
Leandro Ferreira Pereira is CEO and founder of WINNING Scientific Management. He has more than 18 years of experience in senior management positions in management consulting companies and university academic activity. With a degree in Management Informatics from the University of Minho and a PhD in Project Management from the Pontifical University of Salamanca, Leandro Pereira has in his curriculum several of professional and academic distinctions, among which, the best national manager award (from Best Team Leaders), the University Senate Award for having been the best student of the University and the National Prize "Youth and National Defense awarded by the Ministry of Defense". Currently, he divides his professional activity between management consulting, the academy, and advisory various entities, in particular, the Court of Auditors, and has supervisor of dozens of doctoral and master students.

Vânia Patrício is the founding partner of Winning Management Consulting. At the academic level, she is developing research leading to a PhD degree in Management at ISCTE. She has a degree in Business Communication from ESCS. Later she held a postgraduate degree in Marketing and Commercial Management of Financial Services by ISGB and a Postgraduate Degree in Project Management by ISBB. She also holds the PMI Project Management Professional (PMP®) certification and the ROI Institute ROI Professional Certification. She is also certified in International Coaching approved by ICF.

António Teles Fernandes is a founding partner at Winning Scientific Management, a Consulting firm, with responsibilities for the Financial Services sector of the Winning group, having a degree in Organization and Business Management from Universidade Moderna de Lisboa. Later, he completed a Post-Graduation in Project Management from the Instituto Superior Bissaya Barreto of Coimbra, and is currently doing a PhD program - DBA (Doctor of Business Administration) at ISCTE. He has extensive experience in the areas of Project Management, Program Management, Portfolio Management, Organization, Business Analysis, Strategy and Governance, Risk \& Compliance. He is an invited professor on ISCTE and INDEG, lecturing undergraduate and master classes of Strategic Management, Benefits Management, Procurement Management and others. As a trainer, he holds the pedagogical aptitude certificate (CCP), having extensive experience in this area, counting on his curriculum with the design and development of several reference courses in Project Management, Business Analysis and Governance, Risk \& Compliance, also preparing several dozens of candidates for the $P M I \AA(P M P \circledast, P M I-S P \circledast)$ and IIBA® (International Institute of Business Analysis - Canada) certification exams in Portugal. He is CBAP® certified (Certified Business Analysis Professional) by IIBA® (International Institute of Business Analysis), PMP® certified (Project Management Professional) by PMI® (Project Management Institute - USA), MCP certificate (Microsoft Certified Professional: Managing Projects) by Microsoft, ITIL certified by EXIN, CTFL certified and MCI level 1 certified.

José Pedro Santos is a PhD student and Head of Winning LAB the scientific laboratory of Winning Scientific Management. He has an extensive knowledge in management and already published several scientific papers as well presented several papers in international conferences. José, has more than 10 years of professional experience.

Ricardo Alves Santos is a research in the development and evolution of problem solving in organizations. He has a degree in Management from ISCTE and Master in International Management from ISCTE, where he has studied Scientific Management Methods in Organisations. Is currently doing his PhD in Management at ISCTE, developing the topic of Problem Solving as a tool to support strategy adoption in organisations. He is also equity partner of Winning Scientific Management and divides his career between management consulting and academia. Scientific Coordinator of the Master in Information Systems Management at ISCTEM. Invited Professor of the Executive Master in Program and Project Management at INDEG-ISCTE and Invited Professor of Client Engagement and Partnership at Advance Program in Management Consulting. Invited Professor of Procurement, Continuous Improvement, Quality Management and Project Management at ISCTEM (at MBA and Master). PMP® Certificate by PMI®, MCP and MCTS Certificate by Microsoft, MCl Certificate. He is mentor, guest speaker in several management events.

Carlos H. Jerónimo is a Portuguese professor of strategic management and project management at ISCTE in Lisbon. His research covers a wide range of areas: Portfolio Management, Organizational Behavior, Public Sector Modernization, and Citizen Driven Theories. However, he is best known in academia and requested by several European companies in the contribution of the evolution and reinvention of business models. He has a degree in Computer Science and Telematics from Univ. de Aveiro and a Ph.D. in Business Administration and Management from ISCTE, founding partner of Winning Scientific Management, has divided his career between management consulting and academia. He is a mentor, guest speaker in several management events. He was also Vice President of PMI Portugal from 2015 to 2018.

Francisco Simões has an Executive Master in Program and Project Management from ISCTE Executive Education (Lisbon, Portugal) and a Degree in Public Administration and Territory Policy from ISCSP-UTL (Lisbon, Portugal). $\mathrm{He}$ is passionate about helping organizations find funding to leverage innovative, technological and sustainable projects. Throughout a journey of more than 7 years of experience in project management, preparation of applications for funding and coordination of teams, considers it essential to lead by example, with humility, critical thinking, and creativity. 